\title{
Perinatal Grief Among Poor Rural and Urban Women in Central India
}

This article was published in the following Dove Press journal:

International Journal of Women's Health

\author{
Lisa R Roberts $\mathbb{D}^{\prime}$ \\ Solomon J Renati $\mathbb{D}^{2}$ \\ Shreeletha Solomon (D) $^{3}$ \\ Susanne Montgomery ${ }^{4}$ \\ 'School of Nursing, Loma Linda \\ University, Loma Linda, CA, 92350, USA; \\ ${ }^{2}$ Psychology Department, Veer Wajekar \\ A. S. \& C. College, University of Mumbai, \\ Navi Mumbai, 400702, India; ${ }^{3}$ Martin \\ Luther Christian University, Shillong, \\ Meghalaya, 793006, India; ${ }^{4}$ School of \\ Behavioral Health, Director of Research, \\ Behavioral Health Institute, Loma Linda \\ University, Loma Linda, CA, 92350, USA
}

Correspondence: Lisa R Roberts Loma Linda University School of Nursing, I 1262 Campus Street, Loma Linda, CA, 92350, USA

Email Iroberts@llu.edu
Purpose: Given the pressures surrounding women's reproductive role in India, and persistent high rates of perinatal death, the purpose of this study is to describe and compare poor rural and urban Indian women's experiences of perinatal grief.

Participants and Methods: Two cross-sectional studies were compared on shared quantitative variables. Poor rural $(\mathrm{N}=217)$ and urban, slum-dwelling $(\mathrm{N}=149)$ Central Indian women with a history of stillbirth, and/or infant death were recruited with the aid of local community health workers. Trained, local, gender, and linguistically matched research assistants conducted the structured interviews. Shared quantitative variables include demographics, Social Provision Scale, Shortened Ways of Coping-Revised, Perinatal Grief Scale, social norms and autonomy.

Results: While similar with respect to SES, age, number of living sons and perinatal loss experiences, these samples of poor women differed significantly across many variables, most notably women's household position, joint family living, number of live daughters, religious coping, autonomy, and degrees of perinatal grief. While perinatal grief was significantly associated with many variables bi-variably, most lost their relative influence in our stepwise multivariable modeling within site (rural/urban), with only social norms and social support remaining significant for rural (31\% of variance) and wishful thinking and social norms for urban participants (38.4\% of variance). In the combined sample household position, social support and social norms remained significant and explained $53.6 \%$ of the adjusted variance. Conclusion: In both samples, perinatal grief was high following perinatal loss. Both groups of women with perinatal loss have increased risk of mental health sequelae. Notably, the context affected how they experienced perinatal grief, with rural women's grief being higher and more affected by their societal pressures and isolation. Such nuances are important considerations for much-needed tailored approaches to future interventions.

Keywords: stillbirth, infant death, bereavement, maternal, mental health risk

Globally, annually an estimated 5.1 to 5.3 million stillbirths and neonatal deaths occur, the majority of which are preventable and primarily occurring (98\%) in lowand-middle-income countries (LMICs). ${ }^{1,2}$ Slow progress has been made to reduce stillbirth and neonatal death rates, particularly in LMICs. As of 2015, these deaths still contributed almost $50 \%$ of the under- 5 mortality, affecting progress towards meeting the 2030 United Nation's Sustainable Development Goal (SDG) 3.2, to stop preventable stillbirth, newborn deaths, and mortality among children less than five years old. ${ }^{3-5}$

India is among the five countries that have the highest number of under- 5 deaths and together with Nigeria account for almost a third of all deaths in this age group. ${ }^{6}$ 
Though some progress has been made, with an annualized $-3.44 \%$ rate of change in India from 1990 to $2015 .^{5}$ Not only does India have the world's highest number of stillbirths, it also has its highest neonatal death rate. ${ }^{4,7-9}$ The current stillbirth rate is estimated at 25.3 per 1000 live births ${ }^{10}$ neonatal deaths (within the first 28 days of life) at 29.06 per 1000 live births, and post-neonatal ( $>28$ days to 1 year of life) at 11.74 per 1000 livebirths. ${ }^{5}$ Also, not only do national averages conceal variance in regional rates, underestimates are likely, partially due to reluctance to report these outcomes, and varying definitions as to what to count as stillbirth and neonatal death, add to this likely inaccuracy. ${ }^{8,11,12}$

Risk factors for stillbirth and infant death (neonatal and post-neonatal death combined) in low-and-middle-income countries (LMICs) include young or advanced maternal age, higher parity, lack of prenatal care, short birth intervals, and malpresentation..$^{9,10,13,14}$ Additional known contributing factors to perinatal loss (stillbirth and infant death) in India include poor maternal health and nutrition, sanitation issues, and delays in receiving health care or referral to specialty care after reaching a health care facility. ${ }^{15,16}$ In LMICs perinatal loss includes a high percentage of intrapartum stillbirths (baby's death occurs during birth), as opposed to fetal death occurring during the last trimester of pregnancy resulting in stillbirth. ${ }^{17}$ Intrapartum stillbirth when the anticipation of birth and the trauma of unexpected death coincide, increasing the acute bereavement and risk of complications. ${ }^{18}$ Further aggravating grieving related to infant death, women's status in India is historically tied to producing offspring, and likely further complicated by son preference. ${ }^{19-21}$ Even when such tragic loss occurs, women are simply expected to try again and "move on".

Globally, perinatal loss and grief results in a number of mental health sequalae including prolonged or complicated grief, anxiety, depression, posttraumatic stress, suicidal ideation, and marital disruption. ${ }^{22-29}$ Years ago, perinatal grief was characterized as a Western phenomenon, ${ }^{30}$ however, affected mothers are now recognized across cultures, including India. ${ }^{31-35}$

Adding insult to injury, women in India who fail to produce offspring or lose their offspring are often stigmatized, blamed, lose status, face discrimination, mistreatment, and abandonment or divorce, on top of their own misplaced guilt of having inadvertently contributed to this loss. ${ }^{22,25,33,36,37}$ Blaming the woman is common in many cultures including low income as well as Western societies, as it is intertwined with patriarchy, and complicates the grieving process after perinatal loss by suppressing the expression of grief. ${ }^{38}$ As women are expected to do most of the household work in India, the expectation to quickly move on from perinatal loss despite grief its mental health impacts further affects their daily lives. ${ }^{22,39}$ This further undermines the women's ability to function in their expected roles and puts them at risk for domestic violence, ${ }^{40}$ though few studies have explored if this differs in rural vs urban areas of India.

Many health outcomes, but especially vulnerable women's health outcomes are intrinsically related to poverty. India has difficulty providing even basic health care to urban slum dwellers, who have fared poorly in human development indicators and health outcomes. Data from the NFHS showed that women's reproductive health has improved some among the urban non-poor, but among urban-slum residents progress is slow. ${ }^{41}$

For the poor Mumbai slum residents, healthcare expenditures can be catastrophic, requiring more than $40 \%$ of the total household income. Poor, slum-dwelling families often have to use savings or borrow money to pay for maternal health services, increasing the risk of both worsened and ongoing poverty. ${ }^{42}$

While poverty critically affects Indian women's health, it is also intrinsically linked to their status in society, which is even more true for those living in a rural area where poverty abounds and maternal and reproductive health outcomes are generally poorer than in urban areas. ${ }^{43}$ This is in part explained with home births remaining common due to beliefs that pregnancy is natural state of health and fear of institutions. ${ }^{44}$ According to the fourth National Family Health Survey (NFHS IV), in 2015-2016, having a skilled birth attendant present for births is more likely among all urban $(90 \%)$ than rural $(78 \%)$ women. ${ }^{43}$

Populations living in urban slums and poor populations in rural areas have less access to maternal and reproductive health services compared to their non-poor counterparts living in the same areas. ${ }^{42,45}$ A recent analysis of the India Demographic and Health Survey 2015-16 found that rural women were more likely to experience spontaneous perinatal loss than urban women, while urban women were more likely to have had an abortion than their rural counterparts. ${ }^{46}$

The purpose of this study is to describe and compare poor rural and urban Indian women's experiences of perinatal loss and predictors of risk for perinatal grief. While recognizing the universality of perinatal grief, and the pressures surrounding their reproductive role in India, it is not clear how such experiences differ by context within India. 


\section{Methods}

Mixed-methods studies were conducted in rural villages in the Mungeli District in the state of Chhattisgarh (data collected in 2012), and the slums of Mumbai in the state of Maharashtra (data collected in 2020).

\section{Formative/Qualitative Methods}

In each study, key informant interviews and focus group discussions generated qualitative data used to inform the development of quantitative surveys. ${ }^{33}$

\section{Quantitative Methods}

Based on the identified themes and existing literature, we developed a baseline survey for each study, using validated scales to align with focus group themes, whenever possible. The baseline surveys included demographic questions, and questions about social support, coping, autonomy, social norms, and perinatal grief. In Chhattisgarh, all study materials were translated into Hindi and Chhattisgarhi, and in Mumbai into local languages (Hindi and Marathi, respectively). Non-research team bilingual scholars in each location utilized the independent forward and backward translation technique to complete the translations, ensuring cultural and functional correspondence rather than merely literal translation. ${ }^{47}$

Ethics committee approval from Veer Wajekar A. S. and C. College in India and institutional Review Board (IRB) approval was received from Loma Linda University in the US, in accordance with the declaration of Helsinki, prior to data collection. After obtaining informed consent, research assistants proceeded with structured interviews. Low literacy levels among poor Indian women, and the research naiveté of the target populations in each study location, required the surveys to be conducted as structured interviews. Trained, gender and linguistically matched research assistants read each question and response option aloud and recorded participants' responses verbatim. The current study is a comparison of quantitative results from each site to explore how context (rural vs urban) may affect poor Indian women's experiences of perinatal grief. Participants were rural $(\mathrm{N}=217)$ women from Chhattisgarh and urban $(\mathrm{N}=149)$, slum-dwelling women in Mumbai, of childbearing age (1849), who reported perinatal loss.

\section{Measures}

While both studies included a number of identical variables, the Chhattisgarh study included some variables specific to the village setting and the Mumbai study included mental health variables. Shared variables across the two studies were selected to allow for a comparison of women in rural Chhattisgarh and Mumbai slums.

\section{Descriptive Variables}

Socio-demographic variables included marital status, family structure (extended vs nuclear family and participant's position within the family structure), age, education, religion, socioeconomic status, and occupation. Other items included self-reported health and psychosocial status, reproductive history (age at first pregnancy, number of pregnancies, birth intervals, contraception), and details pertaining to perinatal loss (number of stillbirths and/or infant deaths experienced).

\section{Validated Scales}

The Social Provision Scale (SPS) assesses the perception of social support received from others ${ }^{48}$ using 12 items and four-point (1-4) Likert-type response options, resulting in a scoring range of 12-48 (higher scores indicate more support provision). Previously used in rural Chhattisgarh, India (Cronbach's $\alpha$ of 0.69 to 0.74$),{ }^{49,50}$ the current study's Cronbach's alphas were 0.65 (rural) and 0.80 (urban).

The 14-item Shortened Ways of Coping-Revised (SWC-R), assessed on responses to a Likert-type scale from (0) never used, to (3) regularly used has two subscales, wishful thinking and practical coping, that are aligned with two distinct coping strategies. ${ }^{51,52}$ Scores range from 0 to 21 with higher scores indicating more use of the respective coping strategy. Previous use of the scale in India found it to be acceptable ${ }^{34}$ and the current study's Cronbach's alphas were acceptable as well with 0.72 in our rural women and 0.68 in our urban women.

The 33-item Perinatal Grief Scale (PGS) scale (Likerttype responses of (1) strongly disagree to (5) strongly agree) results in a range from 33 to 165 with higher scores indicating more intense grief. A cut-off score of $\geq 91$ indicates a high degree of grief. Found to be reliable in many countries, including India, ${ }^{50,53,54}$ the current study Cronbach's alphas were 0.90 in the rural sample and 0.93 in the urban sample.

\section{Addition Scales Social Norms}

Previously developed by us in rural India $^{34}$ to measure traditional social norms about maternal role expectations, with higher scores representing more endorsement of traditional social norms. The current study Cronbach $\alpha$ was 
0.67 in the rural sample and 0.50 (acceptable but low) in the urban sample.

\section{Autonomy}

Also previously developed by us in rural India ${ }^{34}$ we assessed autonomy in women with six summed items (higher scores indicate greater autonomy) that performed well with a Cronbach $\alpha$ of 0.66 for rural and 0.71 for urban women.

\section{Socioeconomic Status (SES)}

We assessed SES with a single item indicator: "How do your possessions and home compare to other people in your village/neighborhood?", asking women to respond if they fared worse, same, or better.

\section{Analytic Quantitative Methods}

Descriptive analyses compared women from the rural and urban slum sites. Chi square and $t$-tests were used to determine significant difference between groups. Bivariable associations with perinatal grief and co-variates were conducted using Pearson's correlations to inform multivariate analyses, for model building purposes. Linear regressions then explored significant variables with perinatal grief for each site.

\section{Results}

\section{Participants (Demographics)}

All participants were adult women between the ages of 18 and 49 years old. There were no significant differences between rural $(\mathrm{N}=217)$ and urban $(\mathrm{N}=149)$ in socioeconomic status, age, number of stillbirths (ranging from 0 to 8), number of other perinatal losses (with a range of 0-6), or total combined number of losses (ranging from 1 to 10 ), nor in the number of living sons participants had, which ranged from 0 to 6 . Otherwise, however, these two samples had a number of significant differences.

Rural participants from villages in the Mungeli District of Chhattisgarh mostly identified their household position as a daughter-in-law (77.9\%) and all but one participant lived in a joint-family, whereas participants from Mumbai slums were more likely to self-identify as wives (68.5\%) and less than half (47\%) lived in a joint-family structure. Rural women were more likely to be illiterate than urban women (52.5\% and $14.8 \%$, respectively). While nearly all of our rural participants were Hindu (99.5\%) our urban sample was more diverse with nearly $50 \%$ being Hindu, $36.9 \%$ being Muslim and $1.4 \%$ being Buddhist. Fewer rural women reported health problems overall, but were more likely to report malaria than urban women, and were more likely to use tobacco, paan (betel leaf with areca nut), or both. More rural women admitted to being victims of domestic violence $(20.3 \%$ vs $1.3 \%)$ and were more likely to have short birth intervals $(82.5 \%$ vs $36.2 \%)$ compared to urban participants. Lack of contraceptive method was high in both groups $(82.5 \%$ in rural women and $77.9 \%$ in urban women), but when a method was used rural women were more often sterilized (11.5\% vs $5.4 \%)$, and urban women were more often used other means which included pills (13.4\%). Additionally, urban women were older at first delivery, had fewer total pregnancies, and fewer daughters (see Table 1 for details).

\section{Variables of Interest Independent Samples $t$-Tests}

The rural and urban samples of women who experienced perinatal loss were significantly different on all scale variables (Table 2). Rural women were more likely to endorse traditional social norms, had less autonomy, perceived less social provision of support, and employed a lower level of coping strategies (both wishful thinking and practical coping), with a much higher average perinatal grief score than urban women. The rural sample's perinatal grief $(\mathrm{M}=$ 110.84, SD 17.40) exceeds the cut-off score of 91 , whereas the urban sample's perinatal grief was lower $(\mathrm{M}=78.75$, SD 26.97).

\section{Bivariate Analysis of Perinatal Grief}

We explored independent variables associated with perinatal grief using Pearson's correlation analyses separately for each sample. Variables significantly associated with perinatal grief in the rural sample included birth intervals $(-0.135, p=$ $0.048)$, participant's age at first delivery $(-0.146, p=$ $0.033)$, social provision of support $(-0.238, p=0.000)$, wishful thinking $(0.154, p=0.024)$ and practical $(0.204$, $p=0.003)$ coping strategies, autonomy $(-0.146, p=0.033)$, and social norms $(0.518, p=0.000)$. In the urban sample, significantly associated variables included, number of stillbirths $(0.261, p=0.026)$, total number of combined losses (0.303, $p=0.009)$, social provision of support $(-0.307, p=$ $0.010)$, wishful thinking $(0.343, p=0.003)$, and social norms $(0.292, p=0.021)$. Of note, three independent variables were significantly associated with perinatal grief in both the rural bivariate analyses and the urban bivariate analyses, with congruent directionality; social provision of support 
Table I Demographics

\begin{tabular}{|c|c|c|c|}
\hline \multirow[t]{2}{*}{ Characteristics } & \multirow{2}{*}{$\begin{array}{l}\text { Rural (N = 217) } \\
\mathbf{N}(\%)\end{array}$} & \multirow{2}{*}{$\begin{array}{l}\text { Urban }(N=149) \\
N(\%)\end{array}$} & \multirow{2}{*}{$\begin{array}{l}\text { Comparison by } X^{2} \text { or } t \text {-Test } \\
p \text { value }\end{array}$} \\
\hline & & & \\
\hline Household position & & & 0.000 \\
\hline Head-of-Household & I (0.5) & $\mathrm{I}(0.7)$ & \\
\hline Wife & $46(21.2)$ & $102(68.5)$ & \\
\hline Daughter-in-law & $169(77.9)$ & $25(30.2)$ & \\
\hline Daughter & $\mathrm{I}(0.5)$ & I (0.7) & \\
\hline Family style & & & 0.000 \\
\hline Nuclear & $\mathrm{I}(0.5)$ & $78(52.3)$ & \\
\hline Joint-family & $216(99.5)$ & $70(47.0)$ & \\
\hline Education & & & 0.000 \\
\hline Illiterate & II4 (52.5) & $22(14.8)$ & \\
\hline Primary & $47(21.7)$ & $54(36.2)$ & \\
\hline Secondary & $38(17.5)$ & $47(31.5)$ & \\
\hline Higher secondary or above & $18(8.3)$ & $26(17.4)$ & \\
\hline Religion & & & 0.000 \\
\hline Hindu & $216(99.5)$ & 74 (49.7) & \\
\hline Muslim & - & $55(36.9)$ & \\
\hline Buddhist & - & $17(11.4)$ & \\
\hline Other & $\mathrm{I}(0.5)$ & $3(2.0)$ & \\
\hline Comparative SES & & & 0.747 \\
\hline Worse & $28(13.0)$ & $17(11.4)$ & \\
\hline Same or better & I $88(86.6)$ & $132(88.6)$ & \\
\hline Health problems & & & 0.006 \\
\hline None & $139(64.1)$ & $85(57.0)$ & \\
\hline Anemia & $37(17.1)$ & $34(22.8)$ & \\
\hline Malaria & $14(6.5)$ & I (0.7) & \\
\hline Other & $27(12.4)$ & $29(19.5)$ & \\
\hline Tobacco/Paan & & & 0.010 \\
\hline None & $165(76.0)$ & $130(87.2)$ & \\
\hline Uses tobacco/paan or both & $52(24.0)$ & $19(12.8)$ & \\
\hline Victim of DV & & & 0.000 \\
\hline No & $172(79.6)$ & 147 (98.7) & \\
\hline Yes & $44(20.3)$ & $2(1.3)$ & \\
\hline Birth intervals & & & 0.000 \\
\hline$<2$ years & I $79(82.5)$ & $54(36.2)$ & \\
\hline$>2$ years & $37(17.1)$ & $68(45.6)$ & \\
\hline Contraceptive Method & & & 0.000 \\
\hline None & $187(86.2)$ & $116(77.9)$ & \\
\hline Sterilization & $25(I I .5)$ & $8(5.4)$ & \\
\hline Condoms & $3(1.4)$ & $4(2.7)$ & \\
\hline Other & $2(0.9)$ & $20(13.4)$ & \\
\hline & $M(S D)$ & $M(S D)$ & \\
\hline Age & $28.73(7.70)$ & $28.07(4.70)$ & 0.825 \\
\hline Age at first delivery & $18.90(2.47)$ & $20.10(3.24)$ & 0.006 \\
\hline
\end{tabular}

(Continued) 
Table I (Continued).

\begin{tabular}{|l|l|l|l|}
\hline \multirow{2}{*}{ Characteristics } & Rural (N = 2I7) & Urban (N = 149) & Comparison by $\mathbf{X}^{\mathbf{2}}$ or $\mathbf{t}$-Test \\
\cline { 2 - 4 } & $\mathbf{N}(\%)$ & $\mathbf{N}(\%)$ & p value \\
\hline Number of pregnancies & $4.38(2.27)$ & $3.8 I(1.71)$ & 0.006 \\
\hline Number of stillbirths suffered & $1.26(1.00)$ & $1.07(1.12)$ & 0.100 \\
\hline Number of other losses & $0.50(0.82)$ & $0.60(0.76)$ & 0.242 \\
\hline Combined losses & $1.75(1.08)$ & $1.67(1.19)$ & 0.531 \\
\hline Number of living sons & $1.15(1.05)$ & $0.96(0.91)$ & 0.071 \\
\hline Number of living daughters & $1.50(1.47)$ & $1.09(1.00)$ & 0.001 \\
\hline
\end{tabular}

Table 2 Comparing Rural and Urban Women with Perinatal Loss on Variables of Interest Using Independent Samples t-Tests

\begin{tabular}{|c|c|c|c|c|c|}
\hline \multirow[t]{2}{*}{ Parameter } & Rural $N=217$ & Urban $N=149$ & \multirow[t]{2}{*}{$t(256)$} & \multirow[t]{2}{*}{$p$} & \multirow[t]{2}{*}{$95 \% \mathrm{Cl}$} \\
\hline & M (SD) & $M(S D)$ & & & \\
\hline Social norms & $7.16(3.88)$ & $3.22(2.12)$ & 12.03 & 0.000 & {$[3.30,4.58]$} \\
\hline Autonomy & $4.16(1.5 I)$ & $7.70(2.05)$ & -18.00 & 0.000 & {$[-3.93,-3.16]$} \\
\hline Social support & $37.25(4.31)$ & $39.31(6.30)$ & -3.42 & 0.001 & {$[-3.24,-0.87]$} \\
\hline Wishful thinking & $8.82(2.3 \mathrm{I})$ & $11.32(4.12)$ & -6.71 & 0.000 & {$[-3.23,-1.76]$} \\
\hline Practical coping & 7.57 (2.08) & 13.99 (4.09) & -17.66 & 0.000 & {$[-7.14,-5.7 \mid]$} \\
\hline Perinatal grief & I I $0.84(17.40)$ & 78.75 (26.97) & 9.51 & 0.000 & {$[25.39,38.78]$} \\
\hline
\end{tabular}

(negatively correlated in each group), with wishful thinking and social norms positively correlated in each group.

\section{Analysis of Predictors of Perinatal Grief}

Multiple linear regression analysis for the rural sample included significant bivariates of perinatal grief (birth intervals, participant's age at first delivery, wishful thinking and practical coping strategies, social provision of support, and autonomy), which explained $31 \%$ of the variance in grief. Only two independent variables, social provision of support and social norms, remained significant in the model, see Table 3A for details.

Multiple linear regression analysis for the urban sample with significant bivariates (number of stillbirths, combined number of losses, social provision of support, wishful thinking, and social norms), explaining $38 \%$ of the variance in perinatal grief. In this model, wishful thinking and social norms remained significant (Table $3 \mathrm{~B}$ ).

\section{Combined Analyses of Perinatal Grief}

After combining both groups (rural and urban sites), on average the perinatal grief level was high $(\mathrm{M}=100.73, \mathrm{SD}$
24.78). Variables significantly associated with perinatal grief were entered stepwise for multivariate analysis using multiple linear regression. Household position, social provision of support, and social norms remained significant in the final model (Table 4). Variance explained increased with each step from an adjusted $\mathrm{R}^{2}$ of $35.7 \%$ $(\mathrm{p}<0.001)$ to $53.6 \%(\mathrm{p}<0.01)$ in the final model.

\section{Discussion}

This paper examined poor rural and urban Central Indian women's experiences of perinatal grief. These women are vulnerable in terms of multiple social determinants of health that may affect their how they experience perinatal grief and cope with perinatal loss. We explored their experiences of perinatal grief contextually (rural vs urban). A number of similarities were noted in the lives of women from both groups.

All of the study participants had suffered perinatal loss; however, significant differences were found between the poor rural women and the urban slum-dwelling women. Some of these differences can be explained by context, for instance, lower literacy and levels are noted nationally 
Table 3 Summary of Regression Analyses for Variables Predicting Perinatal Grief by Site

\begin{tabular}{|c|c|c|c|}
\hline \multicolumn{4}{|c|}{ A. Rural participants $(N=2 \mid 2)$} \\
\hline Variable & B & SE B & $\boldsymbol{\beta}$ \\
\hline Constant & 130.43 & 14.90 & \\
\hline Birth intervals & -0.04 & 2.78 & -0.00 \\
\hline Age at Ist delivery & -0.49 & 0.42 & -0.07 \\
\hline Social provision of support & -0.69 & 0.23 & $-0.17 * *$ \\
\hline Wishful thinking & -0.19 & 0.52 & -0.03 \\
\hline Practical coping & 0.49 & 0.58 & 0.06 \\
\hline Autonomy & -0.50 & 0.69 & -0.04 \\
\hline Social norms & 2.16 & 0.28 & $0.48^{* * *}$ \\
\hline $\mathrm{R}^{2}$ & \multicolumn{3}{|l|}{0.31} \\
\hline$F$ for change in $R^{2}$ & \multicolumn{3}{|l|}{$13.37 * * *$} \\
\hline \multicolumn{4}{|c|}{ B. Urban participants $(N=138)$} \\
\hline Variable & B & SE B & $\boldsymbol{\beta}$ \\
\hline Constant & 55.78 & $21.4 \mathrm{I}$ & \\
\hline Number of stillbirths & -6.28 & 6.57 & -0.23 \\
\hline Combined number of losses & 11.79 & 5.87 & 0.47 \\
\hline Social provision of support & -0.75 & 0.41 & -0.21 \\
\hline Wishful thinking & 2.95 & 0.78 & $0.41^{* * * *}$ \\
\hline Social norms & 3.12 & 1.49 & $0.23 *$ \\
\hline$R^{2}$ & \multicolumn{3}{|l|}{0.384} \\
\hline$F$ for change in $R^{2}$ & \multicolumn{3}{|l|}{$6.61 * * *$} \\
\hline
\end{tabular}

Notes: (A) $* * p<0.01$, $* * * p<0.001$. (B) $* p<0.05, * * * p<0.001$.

among rural (61.5\%) compared to urban (81.4\%) women, and tobacco use is higher among rural $(8.1 \%)$ vs urban (4.1\%) women. ${ }^{43}$ However, our analyses indicated that these types of demographic variables, though significant in our bi-variable analyses, lost most of their relative influence as they did not add significant variance to the explanatory power (adjusted $\mathrm{R}^{2}$ ) of the model. On the other hand, according to national data rural women are more likely to be victimized by domestic violence, ${ }^{43}$ which is reflected in our data as well. Our rural sample was on average younger than the women in the urban sample at the time of their first delivery, had shorter birth intervals, and more pregnancies, which is consistent with national data indicating that rural women are more likely
Table 4 Summary of Regression Analysis for Shared Variables Predicting Perinatal Grief Among a Combined Sample of Rural and Urban Participants ( $\mathrm{N}=272)$

\begin{tabular}{|c|c|c|c|}
\hline \multirow[t]{3}{*}{ Predictor } & \multicolumn{3}{|c|}{ Perinatal Grief } \\
\hline & \multicolumn{2}{|c|}{ Final Model $4 * *$} & \multirow[t]{2}{*}{$\mathbf{p}$} \\
\hline & $\beta$ & B (SE) & \\
\hline Constant & & $80.59(36.24)$ & 0.030 \\
\hline Site & 0.099 & $5.60(14.99)$ & 0.710 \\
\hline Socioeconomic status & 0.040 & 3.77 (7.99) & 0.639 \\
\hline Religion & -0.098 & $-3.60(3.85)$ & 0.352 \\
\hline Education & -0.077 & $-2.09(2.77)$ & 0.453 \\
\hline Household position & 0.213 & II.44 (4.79) & 0.020 \\
\hline Mother's age at Ist delivery & -0.002 & $-0.03(0.96)$ & 0.977 \\
\hline Domestic violence & -0.149 & $-12.80(7.47)$ & 0.091 \\
\hline Birth intervals & -0.087 & $-5.09(5.68)$ & 0.373 \\
\hline Number of living sons & 0.102 & $3.15(2.67)$ & 0.242 \\
\hline Both stillbirth and infant death & 0.393 & $22.03(12.01)$ & 0.071 \\
\hline Combined number of losses & 0.042 & $0.96(2.19)$ & 0.661 \\
\hline Social support & -0.280 & $-1.18(0.38)$ & 0.003 \\
\hline Practical coping & -0.098 & $-0.63(0.7 \mathrm{I})$ & 0.383 \\
\hline Autonomy & 0.140 & $\mathrm{I} .6 \mathrm{I}(\mathrm{I} .4 \mathrm{I})$ & 0.256 \\
\hline Social norms & $0.266^{*}$ & $2.12(0.89)$ & 0.020 \\
\hline $\mathbf{R}^{2}$ & \multicolumn{2}{|r|}{0.621} & \\
\hline Adjusted $\mathbf{R}^{2}$ & \multicolumn{2}{|r|}{0.536} & \\
\hline F-change statistic & \multicolumn{2}{|c|}{$4.594 * *$} & \\
\hline
\end{tabular}

Note: $* * p<0.01$.

to be married early compared to their urban counterparts, and have more children. ${ }^{43}$ Most of the women in our study (both the rural and urban), did not use any contraception, which is consistent with equally unmet family planning needs among poor rural and urban women nationally. ${ }^{43}$ These contextual consistencies with national data indicate that our participants are fairly representative of the poor population of women in India.

Differences between our rural and urban participants on key variables are interesting. The rural participants were much more likely to agree with traditional social norms related to maternal expectations and had lower levels of autonomy than the urban women. Intuitively, 
this makes sense, as the scale had been developed for use in a study taking place in the rural context, but it is also consistent with findings in the literature. Rural women, who have much-reduced levels of autonomy, are subject to more strictly traditional, patriarchal social norms that define desirably traits of good wives and mothers. ${ }^{55}$ Thus, while gendered socialization occurs among the urban poor as well, ${ }^{56}$ our urban participants were less likely to endorse traditional social norms and had greater autonomy. Similarly, various forms of greater autonomy among urban women have been noted in the literature, including increased mobility, dowry autonomy (women's autonomy to use their dowry), freedom to seek paid work, and having a voice in family decisions. ${ }^{57-60}$ It is important to note, however, that this relative "greater or lesser" autonomy must be understood as degrees of freedom on a very narrow continuum of control over poor Indian women's lives. It is well established that women's reproductive health is affected by their autonomy (status level and empowerment). ${ }^{60}$

In this context, our findings clearly demonstrate that our rural participants had much higher perinatal grief scores in addition to their significant differences in reproductive history compared to the urban participants. Moreover, the rural sample had lower overall use of coping strategies than the urban sample. Both emotion-based (wishful thinking) and practical coping average scores were below the mid-point in the possible range of scores among the rural women, but above the mid-point among the urban women who relied a little more on practical coping than wishful thinking. One plausible explanation is that women in the rural setting who lack autonomy may believe that one's life is predetermined, which could blunt their ability to employ innate coping strategies. A more fatalistic view of life and traditional beliefs have been noted to be dominant in rural villages, where maintaining the status quo is influenced by superstition and fatalism. ${ }^{61}$ Endorsement of social norms was a significant predictor of perinatal grief among both rural and urban women, but a much stronger predictor among the rural participants.

On average, perceived social provision of support was well above the midpoint in both groups, reflecting the close-knit communities our participants are a part of in both rural and urban settings. Close-knit communities are a strength of Indian society, where community ties are foundational to the individual's social network and support, in rural and urban settings. ${ }^{62,63}$ Our urban sample, while less likely to be living in a joint-family context, nonetheless reported significantly higher social provision of support than the rural sample. Similarly noted collectivism has been characterized among slum-dwellers as they are known, in lieu of family, to share each other's burdens and to draw strength from each other. ${ }^{64}$ Social provision of support remained a significant predicator of perinatal grief in the combined multivariate analysis, as did endorsement of social norms.

Limitations to note include the eight-year span between the rural data collection in Chhattisgarh and the urban data collection in Mumbai. During this time, significant changes may have occurred in the rural setting, possibly affecting the women either positively or negatively. There is some evidence in the literature that as men migrate out of rural areas in search of livelihoods, leaving the women behind in the head-of-household $(\mathrm{HOH})$ role. ${ }^{57}$ However, as our rural participants were living in a joint family context, it would likely be the mother-in-law that would assume the $\mathrm{HOH}$ role, and it is unknown what affect this would have on the daughters-in-law living in the household. That said, household position was a significant predictor of perinatal grief (with lower household standing being associated with higher grief) in the final model of combined regression analysis, indicating that any change towards $\mathrm{HOH}$ status could be an important factor in the changing rural context.

Furthermore, the data was collected in two different states (Chhattisgarh and Maharashtra), and although they are adjacent to each other in Central India, there are cultural and linguistic nuances that vary from state to state. Additionally, it is apparent that social norms have an important effect on women's lives across rural and urban settings, but the instrument used to measure participants' endorsement of social norms was found to be less reliable in the urban sample. Nevertheless, this paper adds importantly to the literature by describing the importance of social norms, household position, and social provision of support as predictors of risk for elevated perinatal grief for both rural and urban poor Central Indian women.

Our data suggest that our participants across sites clearly suffered from significant perinatal grief due to the complex after-effects of losing a baby. In response to the findings in the rural area, we had offered a 5-week, low-dose mindfulness intervention that was found to be effective. ${ }^{35}$ In the context of our rural findings (99.5\% Hindu), mindfulness was found to be an acceptable modality, making use of the mind-body connection in women's religious practice while avoiding highly stigmatized 
mental health interventions. ${ }^{65}$ Furthermore, by training local nurses to teach the intervention, it was potentially scalable and sustainable. When working with poor women in the slums of Mumbai, however, we wanted to first explore the possibility of transferring this intervention. Our data suggest that women with the same background of perinatal loss and poverty in Central India, while similar in some respects (household position, social provision of support, and endorsement of social norms), location (urban vs rural) by itself took a prominent role in explaining perinatal grief. Clearly addressing the important needs of women in the slums of Mumbai requires a modified approach to much-needed interventions.

While it is not realistic to influence the pronatalist societal context, women with reproductive challenges could benefit from interventions that help them optimize their overall wellness and perception of social support within their cultural context. Given the identified needs, our next aim is to identify and culturally tailor an intervention that builds on their strengths and aids them in enhancing their wellbeing.

\section{Conclusions}

Reproductive outcomes are inherently tied to women's mental health in pronatalist societies. Overall, poor Indian women who have suffered reproductive loss (by stillbirth, infant death, or both) have an increased risk for heightened perinatal grief depending on their household position, social support, and endorsement of social norms. However, important differences were noted between women from rural and urban settings calling for a modulated response. Greater understanding of the predictors of perinatal grief, subsequent mental health issues, and contextual nuances should inform future appropriately tailored approaches to much-needed interventions that given the contextual pressures of the women should include self-help, community-based interventions for resilience.

\section{Disclosure}

The authors report no conflicts of interest in this work.

\section{References}

1. Akuze J, Blencowe H, Waiswa P, et al. Randomised comparison of two household survey modules for measuring stillbirths and neonatal deaths in five countries: the Every Newborn-INDEPTH study. Lancet Global Health. 2020;8(4):e555-e566. doi:10.1016/S2214-109X(20) 30044-9
2. Wang H, Liddell CA, Coates MM, et al. Global, regional, and national levels of neonatal, infant, and under-5 mortality during 1990-2013: a systematic analysis for the Global Burden of Disease Study 2013. Lancet. 2014;384(9947):957-979. doi:10.1016/S01406736(14)60497-9

3. Frøen JF, Friberg IK, Lawn JE, et al. Stillbirths: progress and unfinished business. Lancet. 2016;387(10018):574-586. doi:10.1016/ S0140-6736(15)00818-1

4. Liu L, Oza S, Hogan D, et al. Global, regional, and national causes of under-5 mortality in 2000-15: an updated systematic analysis with implications for the sustainable development goals. Lancet. 2016;388 (10063):3027-3035. doi:10.1016/S0140-6736(16)31593-8

5. Wang H, Bhutta ZA, Coates MM, et al. Global, regional, national, and selected subnational levels of stillbirths, neonatal, infant, and under-5 mortality, 1980-2015: a systematic analysis for the Global Burden of Disease Study 2015. Lancet. 2016;388(10053):1725-1774.

6. WHO. Children: improving survival and well-being. Newsroom Factsheet; 2020. https://www.who.int/news-room/fact-sheets/detail/chil dren-reducing-mortality\#: :text=Children $\% 20$ under $\% 20$ the $\% 20$ age $\%$ 20of $\% 205 \&$ text $=$ The $\% 20$ total $\% 20$ number $\% 20$ of $\% 20$ under, $1990 \%$ 20to\%2038\%20in\%202019. Accessed October 14, 2020.

7. Blencowe H, Cousens S, Jassir FB, et al. National, regional, and worldwide estimates of stillbirth rates in 2015, with trends from 2000: a systematic analysis. Lancet Global Health. 2016;4:e98e108. doi:10.1016/S2214-109X(15)00275-2

8. Sankar M, Neogi S, Sharma J, et al. State of newborn health in India. J Perinatol. 2016;36(s3):S3. doi:10.1038/jp.2016.183

9. Swaminathan A, Fell DB, Regan A, Walker M, Corsi DJ. Association between interpregnancy interval and subsequent stillbirth in 58 low-income and middle-income countries: a retrospective analysis using demographic and health surveys. Lancet Global Health. 2020;8(1):e113-e122. doi:10.1016/S2214-109X(19)30458-9

10. Saleem S, Tikmani SS, McClure EM, et al. Trends and determinants of stillbirth in developing countries: results from the Global Network's Population-Based Birth Registry. Reprod Health. 2018;15(S1):100. doi:10.1186/s12978-018-0526-3

11. Roy MP. Mitigating the stillbirth challenge in India. Lancet. 2016;387 (10032):1995. doi:10.1016/S0140-6736(16)30460-3

12. Temmerman M, Lawn JE. Stillbirths count, but it is now time to count them all. Lancet. 2018;392(10158):1602-1604. doi:10.1016/ S0140-6736(18)32342-0

13. Dandona R, Kumar GA, Akbar M, Bhattacharya D, Nanda P, Dandona L. Deferred and referred deliveries contribute to stillbirths in the Indian state of Bihar: results from a population-based survey of all births. BMC Med. 2019;17(1):1-17. doi:10.1186/s12916-019$1265-1$

14. Duffy CR, Moore JL, Saleem S, et al. Malpresentation in low- and middle-income countries: associations with perinatal and maternal outcomes in the Global Network. Acta Obstet Gynecol Scand. 2019;98(3):300-308. doi:10.1111/aogs.13502

15. Bapat U, Alcock G, More NS, Das S, Joshi W, Osrin D. Stillbirths and newborn deaths in slum settlements in Mumbai, India: a prospective verbal autopsy study. BMC Pregnancy Childbirth. 2012;12(1):39. doi:10.1186/1471-2393-12-39

16. More NS, Bapat U, Das S, et al. Community mobilization in Mumbai slums to improve perinatal care and outcomes: a cluster randomized controlled trial. PLoS Med. 2012;9(7):1-12. doi:10.1371/journal. pmed. 1001257

17. Baschieri A, Gordeev VS, Akuze J, et al. "Every Newborn-INDEPTH" (EN-INDEPTH) study protocol for a randomised comparison of household survey modules for measuring stillbirths and neonatal deaths in five Health and Demographic Surveillance sites. J Glob Health. 2019;9(1). doi:10.7189/jogh.09.010901.

18. Black BP. Stillbirth at term: grief theories for care of bereaved women and families in intrapartum settings. $J$ Midwifery Womens Health. 2020;65:316-322. doi:10.1111/jmwh.13108 
19. Bhalotra S, Brulé R, Roy S. Women's inheritance rights reform and the preference for sons in India. J Dev Econ. 2018;102275.

20. Jeffery P, Jeffery R. Delayed periods and falling babies: the ethnophysiology and politics of pregnancy loss in Rural North India. Anthropol Preg Loss. 1996;17.

21. Milazzo A. Why are adult women missing? Son preference and maternal survival in India. $J$ Dev Econ. 2018;134:467-484. doi:10.1016/j.jdeveco.2018.06.009

22. Bhat A, Byatt N. Infertility and perinatal loss: when the bough breaks. Curr Psychiatry Rep. 2016;18(3):1-11. doi:10.1007/s11920016-0663-8

23. Burden C, Bradley S, Storey C, et al. From grief, guilt pain and stigma to hope and pride-a systematic review and meta-analysis of mixed-method research of the psychosocial impact of stillbirth. BMC Pregnancy Childbirth. 2016;16(1):1-12. doi:10.1186/s12884-016-0800-8

24. Ellis A, Chebsey C, Storey C, et al. Systematic review to understand and improve care after stillbirth: a review of parents' and healthcare professionals' experiences. BMC Pregnancy Childbirth. 2016;16(1). doi:10.1186/s12884-016-0806-2.

25. Gold KJ, Sen A, Leon I. Whose fault is it anyway? Guilt, blame, and death attribution by mothers after stillbirth or infant death. Illness Crisis Loss. 2018;26(1):40-57. doi:10.1177/1054137317740800

26. Goldstein RD, Lederman RI, Lichtenthal WG, et al. The grief of mothers after the sudden unexpected death of their infants. Pediatrics. 2018;141(5):e20173651. doi:10.1542/peds.2017-3651

27. Heazell AE, Siassakos D, Blencowe H, et al. Stillbirths: economic and psychosocial consequences. Lancet. 2016;387(10018):604-616. doi:10.1016/S0140-6736(15)00836-3

28. Huberty JL, Matthews J, Leiferman J, Hermer J, Cacciatore J. When a baby dies: a systematic review of experimental interventions for women after stillbirth. Reprod Sci. 2016;24:1933719116670518. doi: $10.1177 / 1933719116670518$

29. Koopmans L, Wilson T, Cacciatore J, Flenady V. Support for mothers, fathers and families after perinatal death. Cochrane Database Syst Rev. 2013;(6). doi:10.1002/14651858.CD000452.pub3.

30. Mehta L, Verma I. Helping parents to face perinatal loss. Indian J Pediatr. 1990;57(5):607-609. doi:10.1007/BF02728696

31. Gopichandran V, Subramaniam S, Kalsingh MJ. Psycho-social impact of stillbirths on women and their families in Tamil Nadu, India - a qualitative study. BMC Pregnancy Childbirth. 2018;18(1):N. PAG-N.PAG. doi:10.1186/s12884-018-1742-0

32. Mammen OK. Women's reaction to perinatal loss in India: an exploratory, descriptive study. Infant Ment Health J. 1995;16 (2):94-101. doi:10.1002/1097-0355(199522)16:2<94::AIDIMHJ2280160204>3.0.CO;2-3

33. Roberts LR, Anderson BA, Lee JW, Montgomery SB. Grief and women: stillbirth in the social context of India. Int $J$ Childbirth. 2012;2(3):187-198. doi:10.1891/0886-6708.2.3.187

34. Roberts LR, Montgomery S, Lee JW, Anderson BA. Social and cultural factors associated with perinatal grief in Chhattisgarh, India. J Community Health. 2012;37(3):572-582.

35. Roberts LR, Montgomery SB. Mindfulness-based intervention for perinatal grief in rural India: improved mental health at 12 months follow-up. Issues Ment Health Nurs. 2016;37(12):942-951. doi:10.1080/01612840.2016.1236864

36. Horton R, Samarasekera U. Stillbirths: ending an epidemic of grief. Lancet. 2016;387(10018):515-516. doi:10.1016/S0140-6736(15) 01276-3

37. Shakespeare C, Merriel A, Bakhbakhi D, et al. Parents' and healthcare professionals' experiences of care after stillbirth in low-and middle-income countries: a systematic review and meta-summary. BJOG. 2019;126(1):12-21. doi:10.1111/1471-0528.15430

38. Testoni I, Bregoli J, Pompele S, Maccarini A. Social support in perinatal grief and Mothers' continuing bonds: a qualitative study with Italian Mourners. Affilia. 2020;35(4):485-502. doi:10.1177/ 0886109920906784
39. Pancholi N, Rami B. Care of unfortunate mothers with perinatal loss. Int $J$ Res Med Sci. 2018;6(8):2691. doi:10.18203/2320-6012. ijrms 20183253

40. Rodriguez AL, Stephens DP, Brewe E, Ramarao I, Madhivanan P. A network analysis of domestic violence beliefs among young adults in India. J Interpers Violence. 2019;0886260519889923. doi:10.1177/ 0886260519889923

41. Kumar A, Mohanty SK. Intra-urban differentials in the utilization of reproductive healthcare in India, 1992-2006. J Urban Health. 2011;88(2):311-328. doi:10.1007/s11524-010-9532-7

42. Hazarika I. Women's reproductive health in slum populations in India: evidence from NFHS-3. J Urban Health. 2010;87 (2):264-277. doi:10.1007/s11524-009-9421-0

43. Government of India. National Family Health Survey (NFHS-4) 2015-16: India Fact Sheet. Mumbai: International Institute for Population Sciences; 2018.

44. Dixit P, Dwivedi L. Utilization of institutional delivery services across successive births in India. Int J Popul Stud. 2017;2(2). doi:10.18063/IJPS.2016.02.006

45. Yadav AK, Sahni B, Jena PK, Kumar D, Bala K. Trends, differentials, and social determinants of maternal health care services utilization in Rural India: an analysis from pooled data. Womens Health Rep. 2020;1(1):179-189. doi:10.1089/whr.2019.0022

46. Dongarwar D, Salihu HM. Place of residence and inequities in adverse pregnancy and birth outcomes in India. Int $J$ Maternal Child Health AIDS. 2020;9(1):53.

47. Jones P, Lee J, Phillips L, Zhang X, Jaceldo K. An adaptation of Brislin's translation model for cross-cultural research. Nurs Res. 2001;50(5):300-304. doi:10.1097/00006199-200109000-00008

48. Mosley-Williams A, Lumley MA, Gillis M, Leisen J, Guice D. Barriers to treatment adherence among African American and white women with systemic lupus erythematosus. Arthritis Rheumat. 2002;47(6):630-638. doi:10.1002/art.10790

49. Roberts LR, Montgomery SB, Lee JW, Anderson BA. Social and cultural factors associated with perinatal grief in Chhattisgarh, India. J Community Health. 2012;37(3):572-582. doi:10.1007/s10900-011-9485-0

50. Roberts L, Montgomery S. Mindfulness-based intervention for perinatal grief education and reduction among poor women in Chhattisgarh, India: a pilot study. Interdis J Pract Global Dev. 2016;2(1).

51. Hatton C, Emerson E. The development of a shortened 'ways of coping' questionnaire for use with direct care staff in learning disability services. Ment Handicap Res. 1995;8(4):237-251. doi:10.1111/j.1468-3148.1995.tb00160.x

52. Mascha K. Staff morale in day care centres for adults with intellectual disabilities. J Appl Res Intellect Disab. 2007;20(3):191-199. doi:10.1111/j.1468-3148.2006.00316.x

53. Potvin L, Lasker J, Toedter L. Measuring grief: a short version of the perinatal grief scale. J Psychopathol Behav Assess. 1989;11 (1):29-45. doi:10.1007/BF00962697

54. Toedter LJ, Lasker JN, Janssen HM. International comparison of studies using the Perinatal Grief Scale: a decade of research on pregnancy loss. Death Stud. 2001;25(3):205-228. doi:10.1080/ 074811801750073251

55. Paul M, Essén B, Sariola S, Iyengar S, Soni S, Klingberg Allvin M. Negotiating collective and individual agency: a qualitative study of young women's reproductive health in Rural India. Qual Health Res. 2017;27(3):311-324. doi:10.1177/1049732315613038

56. Basu S, Zuo X, Lou C, Acharya R, Lundgren R. Learning to be gendered: gender socialization in early adolescence among urban poor in Delhi, India, and Shanghai, China. $J$ Adolesc Health. 2017;61(4):S24-S29. doi:10.1016/j.jadohealth.2017.03.012

57. Choithani C. Gendered livelihoods: migrating men, left-behind women and household food security in India. Gender Place Culture. 2019;1-22. 
58. Pallikadavath S, Bradley T. Dowry, 'dowry autonomy' and domestic violence among young married women in India. J Biosoc Sci. 2019;51(3):353-373. doi:10.1017/S0021932018000226

59. Rai P. The labor of social change: seasonal labor migration and social change in rural western India. Geoforum. 2018;92:171-180. doi:10.1016/j.geoforum.2018.04.015

60. Raman S, Srinivasan K, Kurpad A, Ritchie J, Razee H. "We have to ask and only then do": unpacking agency and autonomy in women's reproductive health in urban India. Health Care Women Int. 2016;37 (10):1119-1137. doi:10.1080/07399332.2016.1140171

61. Venkatesh V, Rai A, Sykes TA, Aljafari R. Combating infant mortality in rural india: evidence from a field study of eHealth kiosk implementations. MIS Q. 2016;40(2):353-380. doi:10.25300/MISQ/ 2016/40.2.04

62. Arora S, Sanditov B Caste as community? Networks of social affinity in a South Indian village. 2009.
63. Dasgupta A, Battala M, Saggurti N, et al. Local social support mitigates depression among women contending with spousal violence and husband's risky drinking in Mumbai slum communities. J Affect Disord. 2013;145(1):126-129. doi:10.1016/j.jad.2012.04.043

64. Andavarapu D, Edelman DJ, Monangi N. Victims or survivors: resilience from the slum Dwellers' perspective. In: Galderisi A, Colucci A, editors. Smart, Resilient and Transition Cities: Emerging Approaches and Tools for a Climate-Sensitive Urban Development. Amsterdam, Netherlands: Elsevier; 2018:320.

65. Roberts LR, Montgomery SB. Mindfulness-based intervention for perinatal grief after Stillbirth in Rural India. Issues Ment Health Nurs. 2015;36(3):222-230. doi:10.3109/01612840.2014.962676

International Journal of Women's Health

\section{Publish your work in this journal}

The International Journal of Women's Health is an international, peerreviewed open-access journal publishing original research, reports, editorials, reviews and commentaries on all aspects of women's healthcare including gynecology, obstetrics, and breast cancer. The manuscript management system is completely online and includes a very quick and fair peer-review system, which is all easy to use. Visit http://www.dovepress.com/testimonials.php to read real quotes from published authors. 